\title{
Caregivers' Knowledge of Environmental Sanitation and Hygiene Practices in the Prevention of Acute Diarrhoea among Under-Five Children in Calabar-South, Cross River State, Nigeria
}

Eno-Obong M. Ndueso ${ }^{2}$, Godwin I. Ogban ${ }^{1 *}$ Anthony A. Iwuafor ${ }^{1}$, Ubleni E. Emanghe ${ }^{1}$, Simon N. Ushie ${ }^{3}$, Regina I. Ejemot-Nwadiaro ${ }^{2}$

${ }^{1}$ Department of Medical Microbiology and Parasitology, University of Calabar, Calabar, Nigeria

${ }^{2}$ Department of Public Health, University of Calabar, Calabar, Nigeria

${ }^{3}$ Department of Medical Microbiology and Parasitology, Nnamdi Azikiwe University, Awka, Nigeria

DOI: $\underline{10.36348 / \text { sjpm.2020.v05i05.003 }}$

| Received: 26.04.2020 | Accepted: 03.05.2020 | Published: 08.05.2020

*Corresponding author: Dr. Godwin I. Ogban

\section{Abstract}

Background: Diarrhoea is currently the second leading cause of childhood mortality globally, after pneumonia. It accounted for $9 \%$ of all under-five deaths which was greater than the mortality arising from malaria, HIV and measles combined. The under-five mortality has continued to spike despite medical intervention protocols. This study was therefore designed to assess Caregivers' knowledge of environmental sanitation and hygiene practices in the prevention of acute diarrhoea among under-five children in Calabar-South, Cross River State, Nigeria. Materials and method: A Caregiver who met the inclusion criteria was enlisted as respondent from each of the 660 households to give a total of 660 respondents. Structured questionnaires were administered to the respondents to collect data. Answers to the questions were numerically weighted and summed up to breakpoints used in categorising the respondents' knowledge of environmental sanitation and hygiene practices into poor, fair and good knowledge. Results: Six hundred and fifty (650) respondents completed the interview. Male under-five children were 352 (54.2\%) and females 298 (45.8\%).Child's age and male sex were statistically significant predictors of occurrence of childhood diarrhoea. Occurrence of acute diarrhoea in under-five children was greatest among children 13 - 24 months149 (67.1\%) and male under-five children 196 (55.7\%) compared to female under-five children 131 (44.0\%). Occurrence of diarrhoea reduced with improved Caregivers' knowledge of environmental sanitation and hygiene practices. Occurrence of diarrhoea was also observed to reduce with improved educational status and income of Caregivers.

Keywords: Caregivers, knowledge, sanitation, hygiene, Calabar, Nigeria.

Copyright @ 2020: This is an open-access article distributed under the terms of the Creative Commons Attribution license which permits unrestricted use, distribution, and reproduction in any medium for non-commercial use (NonCommercial, or CC-BY-NC) provided the original author and sources are credited.

\section{INTRODUCTION}

Diarrhoea which is defined as the passage of 3or more loose or watery stools per day, is currently the second leading cause of childhood mortality globally, after pneumonia [1]. In 2010, it was responsible for the death of 2,195 children daily, more than the mortality arising from HIV, malaria and measles combined [2]. In 2015 , diarrhoea accounted for $9 \%$ of all deaths among children under-five years of age worldwide and children less than 2 years of age living in South Asia and SubSaharan Africa were most vulnerable [3]. In Nigeria diarrhea was ranked the $4^{\text {th }}$ leading cause of death among under-five children in 2014[4].

The disease is usually transmitted through faeco-oral routes involving the ingestion of food and drinks contaminated by faecal matters and other human waste products [5] Poor environmental sanitation and hygiene behaviours and improper handling practices of care-giving commodities by Caregivers are central to the high level of contamination of food and water [6]. A study carried out in Bolivia [7], established lack of caregivers' knowledge of practices related to personal and food hygiene for diarrhoea prevention and improper disposal of faeces as significant risk factors for diarrhoea disease among under-five children. Lack of hand washing with soap, unsatisfactory garbage disposal, inadequate water supply, poor water storage practice among others were risk factors for diarrhoea disease in under-five children in developing countries [8] It has been reported that globally, in 2017, 2.2 billion people used unsafely managed drinking -water, 44 million people depended on surface water as a source of drinking water and 2 out of every 5 people or 3 billion people lack hand-washing facilities at home 
[9]. This constituted a great impediment to effective hygiene and environmental sanitation practices. In 2013, the percentage of households with an improved source of drinking water in Cross River state was $26 \%$ while households with improved sanitary facility were just $10 \%[10]$.

The mortality rate among under-five children in resource poor countries arising from diarrhoea has continued to spike despite emphasis on medical intervention protocols such as immunization, micronutrient supplementation, and antibiotic prophylaxis among others. It is advocated that measures aimed at reducing the incidence of diarrhoeal disease should also emphasize interventions that are beyond the medical approach to include improvement of environmental conditions such as safe water supply, adequate treatment of human waste, hygiene education and food safety [11].

This study was therefore designed to assess Caregivers' knowledge of environmental sanitation and hygiene practices in the prevention of acute diarrhoea among under children in Calabar-South, Cross River State, Nigeria.The general objective of this study determine caregivers' knowledge of environmental sanitation and hygiene practices in the prevention of acute diarrhoea among under-five children in CalabarSouth, Cross River State, Nigeria. The outcome of this study has uncovered the areas of strength and weakness in Caregivers' knowledge of environmental sanitation and hygiene practices vis-à-vis prevention of acute diarrhoea among under five children in the study area. These findings when harnessed and appropriately applied will engender a remarkable reduction in the incidence of childhood diarrhoea and attendant high mortality rate in the study area.

\section{MATERIALS AND METHOD}

\section{Study design}

It was a descriptive cross sectional study employed to determine caregivers' knowledge of hygiene practices in the prevention of acute diarrhoea among under-five children. Six wards were chosen from the study area and 10 streets selected from each of the wards to sum up to 60 streets. Eleven compounds were selected per street to give a total of 660 compounds. A household with an under-five child or children was selected per compound to give 660 households. A Caregiver from each of the selected households on giving consent was enlisted into in the study, giving a total of 660 respondents. Semistructured questionnaires were used to collect data from the respondents.

\section{Study location}

The study was carried out in Calabar-South Local Government Area of Cross River state, Nigeria with headquarters at Anantigha. The area was majorly a semi urban settlement, with poor residential planning. Planned drainage system was scarce and mostly illconstructed open gutters. There was no pipe borne water delivery system, no well-defined waste disposal system and blocked drainages with indiscriminately dumped plastic and organic wastes were common sights. The area was predominantly inhabited by the Efiks, Ibibios, Quas, Efuts and settlers of other Ethnic nationalities. In 2011, the population of the area was $222,151[12]$ which were estimated at an annual growth rate of $2.6 \%$ to 888,939 currently. The area has a total of 12 wards and is bounded to the north by Calabar municipality, the south by Cross River, the east by the Great Qua River and the west by Calabar River.

\section{Study duration: This study was carried out $10^{\text {th }}$ November, 2018 and 18th April, 2019.}

Sample size: Six hundred and sixty (660) Caregivers of under-five children in 6 out of 12 wards of the study area,

\section{Calculation of Sample size}

Sample size for this study was determined using the formula [13]

$\mathrm{N}=\frac{\mathrm{Z}^{2} \mathrm{pq}}{\mathrm{d}^{2}}$

Where $\mathrm{N}=$ Sample size, $\mathrm{Z}=1.96$ (i.e. $95 \%$ confidence interval), $\mathrm{d}=0.03$ (margin of error),

$\mathrm{P}=0.08$ (prevalence of diarrhoea in under five) (NDHS, 2013). $\mathrm{Q} \quad=1-\mathrm{p}=0.92$

Therefore, $\mathrm{N}=(1.96)^{2} \times 0.08 \times 0.92$

$$
(0.03)^{2}=314.11
$$

To enhance the validity of the study, the initial sample size of 314.11 was multiplied by 2 to give a sample size to 628 . To account for a perceived non response rate of $5 \%$, the final sample size was 660 .

\section{Selection method}

Multi-stage selection method was used to select ward, street, house-hold and respondents. 


\section{Stage 1: Selection of wards}

The study area had 12 wards. Each ward was assigned a number and lots were casted to select 6 wards out of the 12 wards.

\section{Stage 2: Selection of streets}

Random sampling was employed in the selection of 10 streets per selected ward to give a total of 60 streets.

\section{Stage 3: Selection of Compounds and Households}

Systematic sampling technique was used in the selection of 11 compounds per street to a total of 660 compounds. A household with at least an under-five child was selected per compound to give a total of 660 households.

\section{Stage 4: Selection of respondents}

A respondent (Caregiver) was randomly selected per household to give 660 respondents who were voluntarily enlisted into the study.

\section{Inclusion criteria}

A respondent must

- Currently be an under-five Caregiver

- Be of either sex

- Have ability to communicate

- Give informed consent

\section{Exclusion criteria}

- Refusal to give consent

- Severe hearing impairment

- Not currently an under-five Caregiver.

\section{Procedure methodology}

Asemi-structured questionnaire (Appendix 1) was used to collect data from the respondents. This questionnaire was first pretested on $5 \%$ of sample size (33 respondents) selected randomly from Calabar Municipal Local Government Area which was an adjoining Local Government area to the study area, sharing common characteristics. This was done to assess the reliability of the questionnaire, using Cronbach Alpha Test in SPSS. The test result gave a value of 0.717. According to George \&Mallery [13], this value indicated a good level of internal consistency of the variables contained in the questionnaires.

Key terms of the questionnaires were derived using guidelines in a report by UNICEF/World Health Organization [14]. They were interviewer-administered to respondents. They comprised of two sections with 32 items. Section A elicited information on sociodemographic characteristics of respondents (Caregiver and child). Section B covered questions pertaining to childcare practices.

An observation checklist (Appendix 11) adapted from "Core Questions On Drinking Water and Sanitation for Household Surveys" from the
UNICEF/World Health Organization[14] and "Policy Guidelines on Solid Waste Management" of the Federal Ministry of Environment[15] was appropriately modified to suit this study objectives and employed to aid data collection processes.

\section{Definition of operational terms}

Sanitation: In this study, refers to measures necessary for improving and protecting health and wellbeing of individuals through provision of facilities for proper and safe disposal of human and animal faeces, domestic waste, wastewater and stoppage of open defaecation.

Acute diarrhea: In this study, refers to as the passage of three or more watery stool within a period of 24 hours.

Knowledge: refers to facts, information and skills acquired through experience or education.

Caregivers: In this study, refers to parent or guardian of an under-five child. Under five children: In this study refers to children who are 0 to 59 months of age.

\section{STATISTICAL ANALYSIS}

Data was entered and analysed using the Microsoft Excel 2007 and Statistical Package for Social Sciences (SPSS) software version 20 and the analysis captured frequency distributions of variables, graphical representations, charts and tables. The association between variables and the hypothesis was tested using chi - square tool of statistical analysis.

The items used to calculate caregivers' environmental sanitation and hygiene practices were the following questions in section $\mathrm{B}$ (Appendix 1) of the questionnaire (Q13, Q19, Q20, Q23, Q24, Q25, Q26, Q27, Q28, Q30, Q31, and Q32) in addition to the following questions from the observation checklist(Appendix 11) (Q1a, Q1b, Q2a, Q2b, Q2c, Q3c, Q4a, and Q5a). Scores were assigned to each response accordingly and later summed up to get the total score for each individual for the respective question. For Q13 (yes = 2, no = 1, don't know $=0$ ), for Q19 $($ Stream $/$ River $=0$, Well $=0$, Borehole $=2$, Pipeborne water $=1$, Rain water $=0)$, for Q20 (yes $=2$, no $=$ 1 , don't know $=0)$, for Q23 (Always $=2$, Sometimes = 1 , Never $=0$ ), for Q24 (Always $=2$, Sometimes $=1$, Never $=0$ ), for Q25 (Always $=2$, Sometimes $=1$, Never $=0$ ), for Q26 (Always $=0$, Sometimes $=1$, Never $=2$ ), for Q27 (Always $=0$, Sometimes $=1$, Never = 2), for Q28 (Water cistern = 2, Pit latrine = 1, Bush around $=0$, Open places $=0$ ), for Q30 (Always $=$ 2 , Sometimes $=1$, Never $=0$ ), for Q31 (Toilet $=2$, Throw outside $=0$, buried in the compound $=1$, Waste bin =1), and for Q32 (bury in compound = 1, burning $=0$, Government dumpster $=2$ ). While from the observation checklist; Q1a (Yes = 1, No = 0), Q1b (Yes 
$=1, \mathrm{No}=0), \mathrm{Q} 2 \mathrm{a}(\mathrm{Yes}=0, \mathrm{No}=1), \mathrm{Q} 2 \mathrm{~b}(\mathrm{Yes}=0$, No $=1), \mathrm{Q} 2 \mathrm{c}(\mathrm{Yes}=0$, No $=1), \mathrm{Q} 3 \mathrm{c}($ Yes $=1$, No $=0)$, Q4a (Yes = 1, No =0), and Q5a (Yes = 1, No = 0). Scores summation between $1-11$ represented poor environmental sanitation and hygiene practice, $12-21$ represented fair environmental sanitation and hygiene practice while scores $\geq 22$ represented good environmental sanitation and hygiene practice.

\section{Ethical considerations}

Ethical approval was received from the Cross River State Health Research Ethics Committee, State Ministry of Health, Calabar.

\section{RESULTS}

Caregivers' Socio-demographic data

A total of 650 participants completed the questionnaires giving a response rate of $98 \%$. The bulk of the respondents fell within the age groupings of $21-$ 25 years accounted for $179(27.5 \%), 26-30$ years of age $124(19.1 \%)$ and $31-35$ years of age $205(31.5 \%)$. They were mostly female $583(89.7 \%)$ and predominantly civil servants $152(23.4 \%), 136(20.9 \%)$ artisans and $110(16.9 \%)$ petty traders. They were majorly low income earners with only 29(4.5\%) earning N100,000 local currencymonthly. Over half the population $334(51.4 \%)$ were married.Table1.

Table-1: Caregivers' Socio demographic data

\begin{tabular}{|c|c|c|}
\hline VARIABLES & FREQUENCY $(n=650)$ & PERCENTAGE (\%) \\
\hline \multicolumn{3}{|l|}{ Caregivers' gender } \\
\hline Male & 67 & 10.3 \\
\hline Female & 583 & 89.7 \\
\hline \multicolumn{3}{|c|}{ Age distribution of Caregivers } \\
\hline $15-20$ years old & 99 & 15.2 \\
\hline $21-25$ years old & 179 & 27.5 \\
\hline $26-30$ years old & 124 & 19.1 \\
\hline $31-35$ years old & 205 & 31.5 \\
\hline$\geq 36$ years old & 43 & 6.6 \\
\hline \multicolumn{3}{|l|}{ Caregivers' education status } \\
\hline No formal education & 72 & 11.1 \\
\hline Primary & 149 & 22.9 \\
\hline Secondary & 300 & 46.2 \\
\hline Tertiary & 129 & 19.8 \\
\hline \multicolumn{3}{|l|}{ Occupation of Caregivers } \\
\hline Petty trading & 110 & 16.9 \\
\hline Artisan/Apprentice & 136 & 20.9 \\
\hline Farming & 54 & 8.3 \\
\hline Business & 84 & 12.9 \\
\hline Civil service & 152 & 23.4 \\
\hline Unemployed & 114 & 17.5 \\
\hline \multicolumn{3}{|l|}{ Marital status } \\
\hline Single & 145 & 22.3 \\
\hline Co-habiting & 97 & 14.9 \\
\hline Married & 334 & 51,4 \\
\hline Divorced & 27 & 4.2 \\
\hline Widowed & 47 & 7.2 \\
\hline \multicolumn{3}{|l|}{ Caregivers monthly income } \\
\hline$<\mathrm{N} 18,000.00$ & 274 & 42.2 \\
\hline $\mathrm{N} 18,000.00-\mathrm{N} 49,000.00$ & 225 & 34.6 \\
\hline $\mathrm{N} 50,000.00-\mathrm{N} 100,000.00$ & 122 & 18.8 \\
\hline$>\mathrm{N} 100,000.00$ & 29 & 4.5 \\
\hline \multicolumn{3}{|l|}{ Religion of Caregivers } \\
\hline Christianity & 577 & 88.8 \\
\hline Islam & 73 & 11.2 \\
\hline \multicolumn{3}{|l|}{ Sex of under-5 childen } \\
\hline Male & 352 & 54.2 \\
\hline Female & 298 & 45.8 \\
\hline \multicolumn{3}{|c|}{ Ages of under-5 year old children } \\
\hline$<1$ month & 19 & 2.9 \\
\hline $1-12$ months & 276 & 42.5 \\
\hline 13- 24 months & 222 & 34.2 \\
\hline 25- 36 months & 79 & 12.2 \\
\hline$>36$ months & 54 & 8.3 \\
\hline
\end{tabular}


The relationship between socio demographic variables of respondents and occurrence of diarrhea in under-five children in the study area

Age of child: The occurrence of acute diarrhoea in under-five children was observed to increase with increasing age of child. There was no occurrence of acute diarrhoea in children < less 1 month old but $117(42.4 \%)$ among children $1-12$ months old, $34(43.0 \%)$ among children 25 - 36 months, $27(50.0 \%)$ among children 37 - 48 months, and peaked at $149(67.1 \%)$ among children13 - 24 months. This relationship was statistically significant $(\mathrm{p}=0.001, \mathrm{df}=$ 8 , and $\left.X^{2}=67.710\right)$.

Gender of child: The occurrence of acute diarrhoea was more, $196(55.7 \%)$ among male underfive children than $131(44.0 \%)$ among the female equivalent. This relationship was statistically significant $\left(\mathrm{p}=0.001, \mathrm{df}=2\right.$, and $\left.\mathrm{X}^{2}=33.641\right)$.

Caregivers' monthly income: The occurrence of acute diarrhoea in under-five children was observed to decrease with increasing socioeconomic status. This relationship was statistically significant $(\mathrm{p}<0.001$, df $=$ 6 and $X^{2}=45.399$ ).

Caregivers' educational status: The occurrence of acute diarrhoea in under-five children was observed to decrease with increasing educational status. The occurrence of acute diarrhoea in under-five children was $46(63.9 \%)$ among caregivers'with no formal education, $112(75.2 \%)$ among caregivers'with primary education, $137(45.7 \%)$ among caregivers'with secondary education and $32(24.8 \%)$. This relationship was statistically significant $\left(\mathrm{p}=0.001, \mathrm{df}=6\right.$, and $\mathrm{X}^{2}=$ 124.406)

\section{The relationship between caregivers' environmental sanitation and hygiene practices and occurrence of acute diarrhoea in under-five children}

The occurrence of acute diarrhoea in underfive children decreased with improved environmental sanitation and hygiene practices. The occurrence of acute diarrhoea was 153 (36.1\%) among caregivers' with good environmental sanitation and hygiene practice as compared to the 174 (77\%) among caregivers' with fair environmental sanitation and hygiene practices. Also, more than half of the respondents $341(52.4 \%)$ admitted to using water cistern toilet facility while others admitted to using pit latrine $271(41.7 \%)$ and surrounding bushes, 38 (5.8\%). Most respondents claimed they always 598 (92\%) or sometimes $52(8 \%)$ washed their hands after using the lavatory. The toilet $362(55.7 \%)$ was the most reported way by which respondents disposed children's stool. Those who discarded faeces in waste bins were 231 $(35.5 \%)$ while those that threw human waste in the open were $57(8.8 \%)$.

Furthermore, respondents said they always 313 (48.2\%), sometimes $244(37.5 \%)$ or never $93(14.3 \%)$ washed their hands after changing baby diapers. There were excreta around the doorstep of 73 (11.2\%) households, the presence of sewage water around 260 $(40 \%)$ of the respondents' houses in addition to presence of garbage around the doorsteps of 352 (54.2\%) of respondents households. Most households had covered $378(58.2 \%)$ wastes storage/disposal containers. Wastes were disposed through burying in 20 (3.1\%), burning $99(15.2 \%)$ or government dumpsters $531(81.7 \%)$. The general surrounding around refuse storage site was sanitary in less than half of the households $314(48.3 \%)$ while most of the households $278(42.8 \%)$ were without window nettings to screen out flies.

Different primary sources of drinking water for general household consumption as reported by respondents in this study include wells $6(0.9 \%)$, boreholes $467(71.8 \%)$ and pipe borne water 177 (27.2\%). Nearly all respondents had covered 630 $(96.9 \%)$ and clean $414(63.7 \%)$ drinking water containers but less than half of respondents 281 (43.2\%) reported to treating their drinking water to make it safer for drinking. Most respondents also said they sometimes $317(48.8 \%)$ or always $333(51.7 \%)$ wash their hands with soap and water before preparing meals for their children. Utensils used for feeding infants were always $476(73.2 \%)$, sometimes $141(21.7 \%)$ or never $33(5.1 \%)$ sterilized. Respondents also reported to always $72(11.1 \%)$, sometimes $120(18.5 \%)$ or never $458(70.5 \%)$ reheated leftover food for their children. Respondents while feeding their children, always 148 (22.8\%), sometimes $278(42.8 \%)$ or never 224 (34.5\%) blew the child's food to cool.

Responses to questions pertaining to caregivers' environmental sanitation and hygiene practices were weighted and collated into breakpoints used to categorize Caregivers' knowledge of environmental sanitation and hygiene practices in relation to occurrence of childhood diarrhoea as shown in Table 2. 
Table-2: Relationship between Caregivers' environmental sanitation and hygiene practices and occurrence of acute diarrhoea in under-five children

\begin{tabular}{|c|c|c|c|c|c|}
\hline \multirow[t]{2}{*}{ Variable } & \multicolumn{3}{|c|}{ Occuerence of acute diarrhoea } & Chi square & P-value \\
\hline & Occurence & $\begin{array}{l}\text { Non- } \\
\text { occurence }\end{array}$ & $\begin{array}{l}\text { Don't } \\
\text { know }\end{array}$ & \multirow{7}{*}{104.092} & \multirow{7}{*}{$<0.001 *$} \\
\hline Poor environmental and hygiene practice & 0 & 0 & 0 & & \\
\hline $\begin{array}{l}\text { Percentages within poor environmental sanitation } \\
\text { and hygiene practices }\end{array}$ & $0 \%$ & $0 \%$ & $0 \%$ & & \\
\hline $\begin{array}{l}\text { Fair environmental sanitation and hygiene } \\
\text { practices }\end{array}$ & 174 & 39 & 13 & & \\
\hline $\begin{array}{l}\text { Percentages within fair environmental sanitation } \\
\text { and hygiene practices }\end{array}$ & $77 \%$ & $17.3 \%$ & $5.8 \%$ & & \\
\hline $\begin{array}{l}\text { Good environmental sanitation and hygiene } \\
\text { practices }\end{array}$ & 153 & 244 & 27 & & \\
\hline $\begin{array}{l}\text { \% within good environmental sanitation and } \\
\text { hygiene practices }\end{array}$ & $36.1 \%$ & $57.5 \%$ & $6.4 \%$ & & \\
\hline
\end{tabular}

*significant at $\mathrm{p}<0,05$

In this study, based on summation of weighted responses from the respondents as a means of assessing and categorising Caregivers' knowledge of environmental sanitation and hygiene practices, only two categories were derived. Caregivers either had good or fair knowledge of environmental sanitation and hygiene practices. No summation of responses indicated poor knowledge of environmental sanitation and hygiene practices. Caregivers with good knowledge of environmental sanitation and hygiene practices had $36.1 \%$ occurrence of acute diarrhoea as against $77 \%$ occurrence recorded by Caregivers with fair knowledge of environmental sanitation and hygiene practices.

Other factors that affect the occurrence of acute diarrhoea among under-five children in the study area

Primary source of drinking water: The occurrence of diarrhea was most prominent among under-five children whose households' main source of drinking water was the well (6)100\%, while the occurrence of diarrhea was comparatively reduced in households whose primary sources of drinking water were boreholes (242) $51.8 \%$ and pipe borne water (79) $44.6 \%$.

Water treatment: Furthermore, the occurrence of diarrhea in under-five children was lesser among households who reported to treating their water in any way to make it safer for drinking $28.5 \%$ (80) as compared to those who did not treat their household drinking water $66.9 \%$ (247).

Covered drinking water containers: The occurrence of diarrhea in under-five children was (20)100\% among households who do not use covered drinking water containers as compared to households who use covered containers $48.7 \%$ (307).

Hand washing practice: The occurrence of diarrhea in under-five children was lower among caregivers who washed their hands with soap and water after using the lavatory $47 \%$ (281), before preparing child meals $26.1 \%$ (87) and after changing baby diapers $39.6 \%$ (124) as compared to those who did not.

Household practices: The occurrence of diarrhea in under-five children was greatest among households who reheat their children's leftover food (65) $90.3 \%$, caregivers who do not sterilize infants feeding utensils (33)100\%, caregivers who were in the habit of blowing child food to cool (129) 87.2\%, households who dispose the children stool by throwing outside (51) $89.5 \%$ and households who buried domestic waste in their compound (14) $70 \%$.

Use of improved toilet facilities The occurrence of diarrhea in under-five children in this study was greatest among caregivers who used unimproved toilet facilities such as bush around 84.2\% (32) followed by caregivers who used pit latrine $73.4 \%$ (199) as compared to caregivers who used water cistern $28.2 \%$ (96) ( an improved toilet facility).

\section{DISCUSSION}

In this study, the percentage occurrence of acute diarrhea in under-five children significantly decreased with improved knowledge of environmental sanitation and hygiene practices (p-value $<0.001$, df $=$ 2 , and $\mathrm{X}^{2}=104.092$ ).

Caregivers with good knowledge of environmental sanitation and hygiene practices had $36.1 \%$ occurrence of acute diarrhoea in under-five children as against $77 \%$ occurrence recorded by Caregivers with fair knowledge. Occurrence of diarrhea was least 96(28.2\%) among respondents who practiced use of water cistern toilets as a means of human waste disposal when compared to $82.4 \%$ in people who practiced open defecation. This finding lent support to the assertion by a study [16] that associated the lack of access to a toilet facility to greater incidence of diarrhoea intheir study population. Over half of the respondents in this study $52.5 \%$ used water cistern toilet 
system. This is higher than that of the studies conducted in Ghana and Cross River State where barely $10 \%$ of households had access to improved sanitary facility such as flushing water closets [10, 17]. It was also the finding in this study that $41.8 \%$ of the respondent stored wastes in uncovered waste disposal containers while $81.7 \%$ disposed their waste in open public dump sites, a report similar to the claim of a study in Ghana which was that $78 \%$ of mothers to under-five children stored wastes in open containers while $88 \%$ disposed them in open community dump sites [17]. The simplest advocated means to diarrhea prevention by health authorities is hand washing with soap and water. In this study, $51.7 \%$ of the respondents admitted to always washing hands with soap and water prior to preparing meals for their children. This rate of practice of hand washing with soap and water in this study $(51.7 \%)$ is similar to the $60 \%$ reported by Asenso-Mensahet and co-workers [17] in Koforidua municipality, Ghana and the $82.3 \%$ reported by a study [18] conducted in Tanzania. Hand washing with soap and water is of great importance because the microorganisms that cause diarrhea in individuals such as E. coli, Shigellaspp, and Salmonella spp can survive for long periods on contaminated hands and fingertips. These organisms could be accidentally transmitted to exposed food or water. Hand washing with soap and water remains one of the cheapest, less time consuming, safe and most effective measures used to check the transmission of infectious diseases $[5,19,20]$. There are reports of body surfaces colonization of neonates at birth, by multidrug resistant Gram negative organisms [21] obtained from organisms colonizing the maternal vagina in pregnancy, acquired during the course of labor and delivery [22]. To this extent, Caregivers must ensure washing of hands with soap and water before feeding the children after body contact with under-five children under their care.

In this study, near all respondents (96.9\%) used covered containers to store water for future use, $63.7 \%$ used clean containers for storage of drinking water while $43.2 \%$ of the respondents treat their water before drinking. These findings are in compliance with the advocacy of the World Health Organization that safe water, environmental sanitation and hygiene practices are interventions to reduce the burden of childhood diarrhea.

This study also revealed that some aspects of Caregivers' and children socio-demographic data were statistically significant predictors of childhood diarrhea in under-five children. Occurrence of childhood diarrhoea reduced with increased income level of the Caregiver ( $\mathrm{p}$-value $<0.001$, df $=6$, and $\mathrm{X}^{2}=45.399$ ). Age of the child is a positive predictor of occurrence of acute diarrhea in under-five children ( $\mathrm{p}$-value $<0.001$, $\mathrm{df}=8$, and $X^{2}=67.710$ ). In this study, there was high percentage occurrence of diarrhea in children 13-24 months of age. This is similar to the finding of a study conducted in Mkuranga, Tanzania ${ }^{18}$ which revealed that the highest prevalence rates of diarrhea among underfives was reported for children aged $12-17$ months, with the peak at $18-23$ months. It was also observed in this study that the male gender in children was a statistically significant predictor of childhood diarrhea ( $\mathrm{p}$-value $<0.001$, df $=2$, and $\mathrm{X}^{2}=33.641$ ). Other significant positive predictors of childhood diarrhea include caregivers' educational status ( $\mathrm{p}$-value $<0.001$, $\mathrm{df}=6$, and $\left.\mathrm{X}^{2}=124.406\right)$ in which incidence of diarrhea decreased with improved Caregiver's educational status.

\section{CONCLUSION}

These findings of this study evoked the need for health authorities to:

- Provide safe drinking water to rural and semi urban communities in Calabar South Local Government Area, as a matter of priority.

- Provide waste disposal facilities to all communities in Calabar South Local Government Area of Cross River State.

- Emphasize sound environmental and hygiene practices to mothers at every antenatal and postnatal visit.

- Put legislation in place that will make it mandatory for sanitary inspectors to from time to time visit rural and semi-urban communities to educate and enforce acceptable sanitation and hygiene practices.

- Establish a monthly State sanitation day during which there will be general cleaning of the environment.

- Ensure enactment of a law to stop open defecation.

\section{Conflict of interest}

No conflict of interest on this study.

\section{Contributions of authors}

WE declare that this study was carried out by the authors listed in the article. All liabilities therein pertaining to the content shall be borne by us. The study was conceptualized by Eno-Obong M. Ndueso, Regina I. Ejemot-Nwadiaro and Godwin I, Ogban. Manuscript was written and designed by Godwin I. Ogban, vetted by Eno-Obong M. Ndueso Regina I. Ejemot-Nwadiaro, Anthont A, Iwuafor, Ubleni E. Emanghe and Simon N. Ushie. Data were collected by all and analyzed by Anthony A. Iwuafor.

\section{REFERENCES}

1. Chola, L., Michalow, J., Tugendhaft, A., \& Hofman, K. (2015). Reducing diarrhoea deaths in South Africa: costs and effects of scaling up essential interventions to prevent and treat diarrhoea in under-five children. BMC Public Health, 15(1), 394.

2. Liu, L., Johnson, H. L., Cousens, S., Perin, J., Scott, S., Lawn, J. E., \& Mathers, C. (2012). 
Global, regional, and national causes of child mortality: an updated systematic analysis for 2010 with time trends since 2000. The Lancet, 379(9832), 2151-2161.

3. Carvajal-Vélez, L., Amouzou, A., Perin, J., Maïga, A., Tarekegn, H., Akinyemi, A., \& Newby, H. (2016). Diarrhea management in children under five in sub-Saharan Africa: does the source of care matter? A Countdown analysis. BMC Public Health, 16(1), 830.

4. Oloruntoba, E. O., Folarin, T. B., \& Ayede, A. I. (2014). Hygiene and sanitation risk factors of diarrhoeal disease among under-five children in Ibadan, Nigeria. African health sciences, 14(4), 1001-1011.

5. Ejemot- Nwadiaro, R. I., Ehiri, J. E., Arikpo, D., Meremikwu, M. M., \& Critchley, J. A. (2015). Hand washing promotion for preventing diarrhoea. Cochrane Database of Systematic Reviews, (9).

6. Pickering, A. J., Julian, T. R., Mamuya, S., Boehm, A. B., \& Davis, J. (2011). Bacterial hand contamination among Tanzanian mothers varies temporally and following household activities. Tropical medicine \& international health, 16(2), 233-239.

7. George, C. M., Perin, J., Neiswender de Calane, K., Norman, W. R., Perry, H., Thomas, P. D., \& Lindquist, E. D. (2014). Risk Factors for Diarrhoea in Children under Five Years of Age Residing in Peri-urban Communities in Cochabamba, Bolivia.American Journal of Tropical Medicine and Hygiene., 91(6):1190-1196.

8. World Health Organization. (2004). Water, Sanitation and Htygiene links to health.

9. World Health Organization. (2019). Inequalities in Access to Water, Sanitation and Hygiene. https://www.who.int>publication. Accessed $14 / 11 / 2018$.

10. Nigeria Demographic and Health Survey. (2013). DHS Final Report, FR293 (2).pdf, Household Population and Housing Characteristics, trends in early childhood mortality (English). dhsprogram.com, Accessed,14/11/2018.

11. Brandt, K. G., Castro Antunes, M. M., Pontes da Silver, G. A. (2014). Acute Diarrhoea: evidencebased management. Journal de pediatria, 91(6): 3643

12. National Population Commission, Nigeria. (2006). Censuses: Population statistics. National and State Population and Housing Tables: 2006 Census
Priority Tables Vol. 1. Available from www.population.gov/index.php/censuses.

13. George, D., \& Mallery, P. (2003). Using SPSS for window step by step: A simple Guide and Reference $\left(4^{\text {th }}\right.$ ed.)

14. WHO/UNICEF. (2006). Core questions on drinking water and sanitation for household surveys. https://apps.who.int.Accessed 14/11/2018.

15. Federal Ministry of Environment. (2005). Policy guidelines on solid waste management. https://tsaftarmuhalli.blogspot.com Accessed 14/11/2018.

16. Yilwan, C. S., Okolo, S. N. (2012). Prevalence of Diarrhoea Disease and Risk Factors in Jos University Teaching Hospital, Nigeria. Annals of African Medicine, 1(4), 217 - 221.

17. Asenso-Mensah, E., Awoyemi, A. O., \& Browne, E. N. L. (2009).The Influence of Environmental Sanitation Practices and Hygiene onthe Incidence of Diarrhoea - The Case of Koforidua Municipality, Ghana. African Journal of Clinical and Experimental Microbiology, 10(1), 56-63.

18. Mashoto, K. O., Malebo, H. M., Msisiri, E., \& Peter, E. (2014). Prevalence, one week incidence and knowledge on causes of diarrhea: household survey of under-fives and adults in Mkuranga district, Tanzania. BMC public health, 14(1), 985.

19. Ayeni, A. O. (2012). Domestic water use, sanitation and diarrhea incidence among various communities of Ikare - Akoko, Southwestern, Nigeria. African Journal of Microbiology Research, 6(14), 3465-3479, retrieved from http://www.academicjournals.org/AJMR

20. Kinge, C. W., \& Mbewe, M. (2010). Characterisation of Shigellaspecies isolated from river catchments in the North West province of South Africa, South. African Journal of Science, 106(11) $1-4$.

21. Ogban, G. I., Iwuafor, A.A, Emanghe, U.E., Ushie, S. N, Agan, T.U. (2018). Body Surfaces Colonization of Newborn Babies with ESBLproducing Enterobacteriaceae on Delivery at Lagos University Teaching Hospital, Lagos, Nigeria. Scholars Journal of Applied Medtcal Sciences, 6(10): 4134-4144.

22. Ogban, G. I., Oduyebo, O. O., Fajolu, I. B., Oshun, P. O., Emanghe, U. E., Iwuafor, A. A., ... \& Agan, T. U. Maternal Vagina Colonization with Extended Spectrum B-Lactamase Producing Enterobacteriaceae in Pregnancy: Any Correlation with ESBL-Positive Early Onset Neonatal Sepsis? 